\title{
A inteireza do ser como caminho para a constituição do sujeito professor
}

\author{
The integrity of being as a way for the constitution of the teacher as a subject
}

La entereza del ser como camino para la constitución del sujeto profesor

ELIANA MARIA DO SACRAMENTO SOARES*

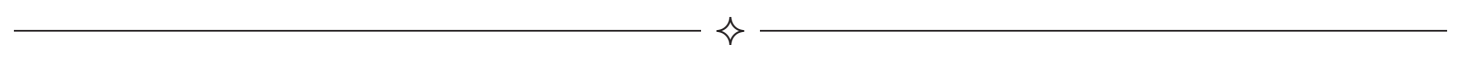

\begin{abstract}
RESUMO
Neste texto, apresentam-se reflexões acerca da constituição do sujeito professor, tomando como caminho teórico a Matriz Biológico-Cultural da Existência Humana. Parte-se do pressuposto de que essa matriz contém conceitos que permitem compreender as diversas dimensões do viver e do conviver humano. Articulando conceitos desse arcabouço, experiências como pesquisadora implicada e vozes de outros atores que investigam o tema, expressa-se a concepção de inteireza do ser, no sentido de um estado de consciência que permite olhar para si com legitimidade e presença a fim de estar com o outro, em convivência e transformação mútua. Nesse caminho reflexivo, propõem-se alguns princípios que podem desencadear processos internos que permitam a emergência desse estado de inteireza, inspirando-se no conceito do conversar liberador. Argumenta-se, para concluir, que, ao atuar desde um estado de presença e em acoplamento com seus alunos, em espaços de convivência, o professor está educando para a paz, numa dimensão que inclui a espiritualidade.
\end{abstract}

Palavras-chave: Inteireza do ser. Constituição do sujeito professor. Conversar liberador. Convivência.

\begin{abstract}
In this text I present my reflections about the constitution of the teacher as a subject, taking as a theoretical path the Biological-Cultural Matrix of Human Existence. I start from the assumption that this matrix contains concepts that allow us to understand the different dimensions of living and living together. Articulating concepts of that scaffolding, my experiences as a committed researcher and the voices of other actors who investigate this subject, I express my conception of integrity of being, in the sense of a state of consciousness that allows one to look at oneself with legitimacy and presence with the purpose of being with the other, in coexistence and in mutual transformation. In this reflective path, I propose some principles that can trigger internal processes that allow the emergence of that state of integrity, inspired by the concept of liberating conversation. To conclude, I argue that by acting from a state of presence and in connection with students, in spaces of coexistence the teacher is educating for peace, in a dimension that includes spirituality.
\end{abstract}

Keywords: Integrity of being. Constitution of the teacher as a subject. Liberating conversation. Coexistence.

\section{RESUMEN}

En este texto presento mis reflexiones acerca de la constitución del sujeto profesor, tomando como camino teórico la Matriz Biológica-Cultural de la Existencia Humana. Parto del presupuesto de que esa matriz contiene conceptos que permiten comprender las diversas dimensiones del vivir y el convivir humano. Articulando conceptos de ese andamiaje, mis experiencias como investigadora comprometida y las voces de otros actores que investigan el tema, expreso mi concepción de entereza del ser, en el sentido de un estado de conciencia que permite mirar a sí mismo con legitimidad y presencia con la finalidad de estar con el otro, en convivencia y en transformación mutua. En ese camino reflexivo, propongo algunos principios que pueden desencadenar procesos internos que permitan el surgimiento de ese estado de entereza, inspirándome en el concepto del conversar libertador. Argumento, para concluir, que al actuar desde un estado de presencia y en acoplamiento con sus alumnos, en espacios de convivencia el profesor está educando para la paz, en una dimensión que incluye la espiritualidad.

Palabras clave: Entereza del ser. Constitución del sujeto profesor. Conversar libertador. Convivencia.

\footnotetext{
* Doutora em Educação pela Universidade Federal de São Carlos, SP. Atua como professora e pesquisadora da Universidade de Caxias do Sul, RS onde também é membro do corpo permanente do Programa de Pós-graduação, Mestrado em Educação.E-mail: emsoares@ucs.br
} 


\section{O CONVITE QUE FAÇO}

Minhas contribuições para pensarmos a construção docente é abordá-la a partir da ideia de inteireza/plenitude do ser. Esse convite é coerente com o meu viver neste momento, e espero encontrar sintonia com os leitores. Assim, o estudo inicia-se falando sobre "o lugar" desde onde apresento minhas reflexões. Atuo como professora da área de Ciências Exatas e Engenharia e do Programa de Mestrado e Doutorado em Educação na linha Educação, Linguagem e Tecnologia da Universidade de Caxias do Sul. Sou membro do Observatório de Cultura de Paz, Direitos Humanos e Meio Ambiente e participante do curso de formação em Constelações Sistêmicas e de Movimentos Essenciais. Este último tem como foco autoconhecimento e autotransformação, buscando criar reconciliação em todos os níveis: cada um com si mesmo, com os aspectos internos e com o entorno.

Inicialmente, apresentam-se algumas considerações teóricas e a seguir aborda-se uma "alternativa" que tem potencial para ampliar a consciência do que se está vivendo no cotidiano e possibilitar a cocriação do ser que quer viver.

Para tanto, tomo a liberdade de me expressar e me deixar tocar pelas percepções e experiências, e sempre que possível articulando minhas ideias com as dos pesquisadores que abordam o tema.

Assim, como professora e pesquisadora implicada no cotidiano acadêmico, tomo alguns conceitos da Matriz Biológico-Cultural da Existência Humana, de Maturana e D'Avila (2009), para iluminar minhas considerações, pois entendo que essa matriz teórica propicia que olhemos as diversas dimensões do viver e do conviver cotidiano, refletindo sobre como somos o que somos em acoplamento conosco e com os outros na convivência. Dessa abordagem, considero que possam surgir possibilidades de práticas com potencial para a constituição do ser professor a partir de sua inteireza. Sendo assim, ele pode ser agente de práticas educativas que levem a uma educação para a paz e que também abranjam a dimensão espiritual.

\section{O CENÁRIO CONTEMPORÂNEO E A ATUAÇÃO DOCENTE}

Os resultados de estudos relacionados à formação do professor, em linhas gerais, indicam que esta precisa ser um processo contínuo e fruto da reflexão sobre a experimentação desses sujeitos, tendo seu contexto de atuação como cenário. Ou seja, que eles, como sujeitos implicados em seu processo de fazer docente, possam ir ressignificando esse fazer, de forma recursiva e em interação com seus pares. Brustolin e Soares (2011) inferem que essas mudanças precisam ser apoiadas por fluxos de interação e de cooperação de forma recorrente, como maneira de sustentar as transformações. Dito de outra forma, os professores precisam constituir-se como observadores de si próprios, num fluir recursivo de reflexão sobre o seu fazer (MATURANA, 2001).

Soares e Valentini (2011) falam dessa maneira de atuar, colocando o sujeito como foco do processo, no qual as transformações em sua forma de ser e de atuar possam surgir como resultado de autoformação, atribuindo significado à experiência vivenciada. Assim, o professor é o sujeito de sua formação, que está em constante vir a ser, e nesta ensinar e aprender são movimentos codependentes de um mesmo fluxo de ações recursivas.

Nesse cenário, ele e seus alunos formam um sistema, acoplado às suas experiências educativas, que convivem $\mathrm{e}$ atuam em parceria entre si e com o meio onde convivem. A partir dessa forma de abordar, ensinar é um processo que acontece na convivência e que vai se sucedendo de forma recursiva, em acoplamento com o outro e com o entorno (MATURANA, 1997, 2001).

Sob essa visão, aprender é se modificar de forma congruente, onde o meio produz mudanças na estrutura e age sobre os sujeitos, alterando-os, numa relação circular: acoplamento estrutural (MATURANA, 1997). E, assim, novas maneiras de ser e de estar no contexto escolar podem ser produzidas, construindo e reconstruindo diferentes alternativas de desenvolver a prática educativa.

No cenário onde tenho atuado, nas escolas e na universidade, percebo o desafio deste momento, que implica lidar com as demandas de diversas ordens no cotidiano acadêmico: as posturas dos alunos, que variam desde a rebeldia, agressividade e apatia, até seu envolvimento e participação. Nossas angústias, frustrações e anseios pessoais se unem ao nosso desejo de motivar o aluno, instigando-o a serem agentes de sua formação e do seu processo de conhecer.

\section{A MATRIZ BIOLÓGICO-CULTURAL DA EXISTÊNCIA HUMANA COMO BASE PARA PENSAR A ATUAÇÃo DOCENTE}

Proponho pensar em alternativas para a constituição do ser professor, tomando como arcabouço conceitual para iluminar esse cenário a Matriz Biológico-Cultural da Existência Humana. Esta se constitui num desdobramento da Biologia do Conhecer, a qual representa uma proposição explicativa que procura mostrar como os processos cognitivos surgem da atuação dos sujeitos enquanto seres vivos.

Esse desdobramento, desenvolvido por Maturana e D’Ávila (2009), convida-nos a olhar as diversas dimensões do viver e do conviver cotidiano, refletindo sobre nossa 
constituição, a partir da nossa forma de ser e de estar com nós mesmos e com os outros na convivência. Para isso, os autores levam em conta a matriz biológico-cultural na qual o sujeito está imerso, enquanto experiência em seu viver cotidiano. Isso significa levar em conta e entender as características do contexto onde atua, as relações que estabelece com o outro, com quem convive e consigo mesmo.

Considero que essa perspectiva teórico-epistemológica da Biologia-Cultural, oferecida por Maturana e D'ávila (2009), contém elementos para pensar, desde diferentes dimensões do viver e do conviver, as situações vividas hoje pelo professor em seu contexto de atuação. A partir dessa abordagem, podemos conceber as desigualdades culturais entre professores e alunos, como sendo diferentes orientações do viver, guiadas pelas emoções e fazeres que constituem determinada forma de viver. No caso, de conviver no ambiente escolar, mediados pelas práticas educativas. Sendo assim, tais práticas precisam ser reconhecidas e consideradas para ser a base a partir da qual possa ser criado um cenário de convivência, onde esses sujeitos, professores e alunos possam se reconhecer e atuar juntos e em sintonia entre si, olhando juntos para aquilo que os leva a estarem juntos, isto é, o processo educativo.

Enfatizo a importância dos movimentos internos do sujeito, na busca de entender e identificar sua forma de ser: o que o motiva, o que o angustia, seus anseios, seus desafios, suas alegrias. Esses movimentos são desencadeados quando o sujeito se deixa afetar pelo desejo de conhecer suas emoções e sentimentos, num processo de auto-observação. Quando isso é colocado em movimento, ele estabelece uma interação mútua e dinâmica com suas sensações e com o meio em que atua, resultando em coordenações de coordenações de ações, de forma que ele opere recorrentemente, com o meio, no meio e consigo mesmo. Nesse fluir, sua estrutura está sempre se moldando ao domínio de ação em que ele desenvolve sua ontogenia, de modo que tudo o que faz, no domínio de suas interações, é determinado por sua estrutura a cada instante (MATURANA e VARELA, 1997).

Sendo assim, podem acontecer mudanças em sua dinâmica interna, como consequência de seus movimentos internos de recursividade e de legitimidade, num processo de operar recorrentemente, denominado acoplamento estrutural. E isso pode ser a matriz de novas condutas (MATURANA e VARELA, 1997; CAPRA e LUISI, 2014), sustentadas por movimentos de autoorganização, que, por sua vez, modificam a dinâmica do ser.

Dito de outra forma, para o sujeito operar de maneira diferente, é preciso que aconteça algo que mude sua organização, sua dinâmica interna. Ele precisa ser perturbado e aceitar essa perturbação, no sentido de esta desencadear um movimento interno de coordenações de ações recursivas, que levam a uma mudança estrutural, ou seja, ao acoplamento estrutural.

Para que essas interações tenham potencial de desencadear transformações, precisam acontecer com presença e consciência, de forma que o sujeito possa estabelecer novas relações consigo mesmo, com o outro e com o entorno/ambiente. Aqui, toma-se o significado de consciência da perspectiva de pesquisadores como Senge et al. (2007), Wheatley (2006a, 2006b), Capra e Luisi (2014) e Varela e al. (2003). Para eles, ser consciente é agir com presença e com atenção e, ao ser consciente de sua forma de atuar, o sujeito pode decidir qual caminho trilhar, com responsabilidade e empoderamento. Compreendo empoderamento a partir da conceituação dada por Paulo Freire, relacionada à capacidade de o indivíduo realizar, por si mesmo, as mudanças necessárias para evoluir e se fortalecer (FREIRE, 1987).

Ao trazer essas ideias para a reflexão acerca do ser professor, considero que o sujeito docente se constitui no fluir de suas operações, enquanto experiência suas práticas docentes, "no seu viver docente", de forma recursiva, no qual sua estrutura é constantemente transformada, de modo congruente com suas interações, consigo e com seu entorno.

Sendo assim, o ambiente de atuação docente e a dinâmica pedagógica formam uma circunstância para se viver no fazer e, mais que isso, para se refletir sobre o fazer: dessa maneira, em interações recorrentes, os professores, em seu entorno, constituem-se, no sentido de se construírem enquanto vivem suas experiências.

Soares e Rech (2009), falando sobre o ambiente de aprendizagem onde atuam professores e alunos, enfatizam que este pode ser entendido como um domínio constitutivo do próprio processo de aprender. Isso porque essas autoras consideram que a aprendizagem acontece como mudanças e transformações estruturais que decorrem de fluxos de interações recorrentes entre professores e alunos, atuando em acoplamento estrutural (MATURANA, 2002).

Dessas considerações, entendo que é no domínio onde vive sua experiência docente, estando consigo, em legitimidade e em sintonia com os alunos, que podem ser criadas formas de ser e de estar no campo da prática docente. Essas formas, para serem coerentes com o conceito de acoplamento estrutural, precisam estar sustentadas por conversações construtivas e acolhedoras, sem negação e julgamento. Maturana (2001) recomenda que a conduta de interações que aceita o outro na convivência é caracterizada por interações que denotam respeito, aceitação do outro em seu espaço de existência, em sua dignidade e legitimidade. 
Essa forma de atuar no espaço educativo requer do professor presença e atenção para que ele possa estar em sintonia com seu aluno. Isso, por sua vez, requer auto-observação, um movimento relacionado ao autoconhecimento que pode propiciar a emergência de posturas internas com o potencial de ampliar a consciência de si. Para que, então, juntos, professores e alunos, se assim escolherem, possam cocriar formas diferentes de convivência e de estar no campo da atuação educativa com presença.

Entendo que a auto-observação e o autoconhecimento dizem respeito a um acoplamento com o ser interno, num estado de inteireza humana. Aqui concebo "inteireza do ser" no sentido de ter consciência daquilo que se move em seu campo interno, olhando para si, para estar presente e em legitimidade com o outro. Ou seja, antes de mais nada, estar em coerência consigo para depois estar com o outro em convivência e em possível transformação mútua.

Isso está em consonância com o que apresenta Andrade (2011) em sua tese de doutorado, cujo tema é a formação integral dos educadores pautada num processo de autoformação. A autora concebe a expressão inteireza do ser, relacionando-a a aspectos humanos e existenciais, entendendo inteireza como um processo resultante não apenas de experiências trazidas de fora de si, para dentro, de exigências externas individuais ou coletivas. Mas também de dentro para fora, da essência do próprio sujeito, a partir de seus interesses, necessidades, valores, imaginação, intuição, crenças, saberes, vinculando-se à sua própria existencialidade. Nos resultados de seu estudo, a autora infere que é possível, ao sujeito, que toma consciência de si e de suas experiências de vida, desenvolver seu processo de autoformação.

Assim, coloco minha ideia de que construímos nossa subjetividade enquanto vivemos, afetando e sendo afetado pelo outro e pelas experiências nas quais atuamos. Essa construção acontece muitas vezes sem nos darmos conta, e os resultados desta aparecem na forma de nossas emoções, sentimentos e movimentos corporais. Nesse sentido, podemos escolher agir sem ter consciência disso ou observando e colocando em movimento nossos recursos para ir transformando nossa forma de ser e de estar nas experiências. É disso que se trata o que estou desafiando com minhas reflexões: ampliação da consciência, no sentido de nos darmos conta de como estamos vivendo e atuando no campo da docência e criarmos novas formas de ser nesse contexto.

Essa forma de entender encontra eco nas palavras de Pellanda (2016), quando ela discorre sobre a "invenção de si", articulando o processo de conhecer com a constituição da subjetividade. A autora destaca que a experiência do subjetivar-se precisa ser vivida em nossa plena potência de seres autopoiéticos, o que significa ir criando nossa forma de ser, a partir de nossa estrutura, de forma orgânica com nossas experiências.

\section{PRINCÍPIOS DO CONVERSAR LIBERADOR PARA INSPIRAR A CONSTITUIÇÃO DOCENTE NUMA PERSPECTIVA DE INTEIREZA DO SER}

Um possível caminho para desencadear o processo de construir a inteireza de si é o conversar liberador (MATURANA e DÁVILA, 2009). Este representa uma conversação que pode tornar consciente aquilo que permeia o campo do sujeito e que se conserva na forma de padrões de pensamento e sentimento nas suas relações, mesmo que de forma inconsciente. $\mathrm{O}$ termo conversação é usado na Biologia do Conhecer (MATURANA, 1997), para se referir à linguagem entrelaçada com o sentir e permeada pela emoção, que é a forma como os seres humanos vivem e se constituem.

Soares e Rech, (2016) referem-se a esse conversar como sendo:

um processo reflexivo que pode revelar como uma pessoa foi criando e mantendo ao longo de sua vida, ainda que de forma inconsciente, o conjunto de suas emoções, de uma forma recursiva. Na maioria das vezes essa criação e manutenção foi alicerçada num sentimento de desamor por si, o qual, por sua vez, foi desencadeado no contexto cultural familiar e social, onde foi criada e vive (p. 44).

Maturana e Dávila (2009) falam das transformações culturais que a humanidade foi realizando ao longo de sua história, mediante a concepção de eras psíquicas. São estas: a Arcaica, a Matríztica, a do Apoderamento, a Moderna, a Pós-Moderna e a Pós-Pós-Moderna. Ao apresentar cada uma destas, os autores mostram que as emoções e tudo o que vivemos em cada era foram sendo construídos num devir entrelaçado de emoção, aspectos culturais e históricos que constituem, dentre outros aspectos, a experiência humana.

Assim, eles argumentam que sentimentos, desejos, emoções, sofrimento, dentre outros, surgem como dimensões psíquicas a partir da forma como compreendemos e entendemos o nosso modo de viver, fazer e estar nas experiências. A isso, os autores denominam a matriz biológico-cultural de cada era, de cada momento da evolução da humanidade.

No caso das reflexões aqui apresentadas, tomarei as emoções e os aspectos culturais das eras recentes, já que permitem inferir que estamos diante de uma "virada". Isso porque os grandes desafios que a humanidade hoje enfrenta, nos diversos setores -educação, economia, saúde, relações humanas -, são consequências de uma visão e forma de agir e de ser que já não consegue nos 
levar além. A racionalidade científica e a objetividade nos levaram a formas de pensar que excluem o observador, conduzindo-nos a uma fragmentação no pensamento humano que desvaloriza os sentimentos, as emoções e a subjetividade. Estes representam alguns aspectos de nossa multidimensionalidade que precisam ser considerados para que possamos ir além e buscar caminhos para a solução dos problemas que nos tocam.

O momento em que vivemos, a era psíquica pósmoderna, é:

a grande oportunidade de escolher um viver e conviver que não negue a autonomia reflexiva e de ação própria a nosso ser seres amorosos, que é o fundamento biológico e psíquico de nosso ser seres humanos éticos (MATURANA e DÁVILA (2009, p. 45).

Assim sendo, parto do pressuposto de que o conversar liberador pode ser uma prática que o sujeito realiza consigo mesmo. Nessa perspectiva, pode ser um caminho para que o ser possa entender sua forma de agir, identificar suas emoções e lidar com estas de forma consciente e responsável. Essas práticas/vivências podem desencadear movimentos internos que, por sua vez, possibilitam processos de autotransformação, de forma que os sujeitos mudem sua forma de agir, pois mudam sua forma de ser.

\section{OS PRINCÍPIOS DO CONVERSAR LIBERADOR PARA PENSAR A PRÁTICA PESSOAL DE BUSCAR A INTEIREZA DO SER COMO FORMA DE CONSTITUIÇÃO DO PROFESSOR}

Considerando as orientações de Maturana e D'Ávila (2009), apresento alguns princípios, baseados nas considerações desses autores para pensar em práticas de constituição do professor desde a sua inteireza. Importante ressaltar que o conversar liberador foi concebido como uma processualidade, tendo como base reflexões, investigações e práticas numa comunidade em Santiago do Chile, em 2000. Assim, surgem de práticas entre sujeitos.

Aqui proponho que essa prática seja considerada para que o sujeito possa olhar para si, num processo de estar consigo e buscar um empoderamento pessoal, e para que, desde sua inteireza, esteja com o outro. Sob essa forma de abordar, inteireza está relacionada a um entendimento de si, desde as várias dimensões que nos constituem como seres humanos. Num sentido de se ver por inteiro, a partir de suas partes constituintes, expressas como emoções e sentimentos, dentre outros aspectos. Sendo assim, no caso específico deste texto, o que proponho é que o professor precisa olhar para si, para buscar seu estado de inteireza, como ponto de partida para estar com seus alunos no conviver educativo.
Um primeiro exercício é relacionado à busca de um estado de inteireza diz respeito a olhar para si, identificando sentimentos, emoções, acolhendo-os sem julgamentos ou expectativas. Isso carece de atenção consciente, pois crenças nos levam a julgamentos e à culpa, ao invés de acolhimento. No contexto dessas práticas que estou propondo, acolher emoções, receios e anseios é importante para que as energias que perpassam esses estados sejam reveladas.

O próximo passo é a escuta, com a corporalidade e suspensão de valores e saberes, num estado de abertura para que algo se manifeste e mostre a realidade da situação. Isso diz respeito a uma permissão para que os aspectos do ser se apresentem, num processo dinâmico, numa dança entre "escutar-sentir-reflexionar-estar inteiros aí” (MATURANA e DÁVILA, 2009, p. 236). É somente quando isso acontece que podem surgir relações colaborativas e coinspirativas e o respeito mútuo de si para consigo mesmo.

Quando isso ocorre, surge o encontro do ser consigo mesmo, e nesse estado o sujeito pode responsabilizar-se pela sua forma de viver e aceitar e compreender aquilo que cria com essa forma de ser, de fazer e de viver que tem experimentado. Forma essa que está imersa num contexto cultural e psíquico. Ao trazer isso para seu entendimento, o sujeito pode escolher atuar desde outro lugar.

Essas práticas podem ser entendidas como um caminho de autoconhecimento num processo de observação de si. Como observador implicado (MATURANA, 2001), o professor pode estar iniciando um caminho que Boettcher e Pellanda (2010) denominam "atitude metacognitiva e potencializadora", no qual, na convivência consigo mesmo, o professor possa refletir sobre seu modo de viver e de ser. Considero que essa prática possibilita que o sujeito professor possa se transformar desde um acoplamento consigo. Sendo assim, pode atuar no cotidiano da vida escolar, a partir de uma forma, transformando-a e sendo transformado.

Enfatizo que essa prática necessita constituir-se de um historial de operações recursivas para que tenha o potencial de provocar mudanças estruturais, que, por sua vez, podem manifestar-se nos modos de agir, interagir, conviver e pensar (MATURANA; VARELA, 1997).

Diante dessas considerações, penso que o professor, partindo de sua inteireza, pode sustentar em sua prática docente vivências caracterizadas pela aceitação do outro, pelo respeito mútuo, pela suspensão de julgamento, pela aceitação da diferença, pela presença sem exigência, além de outras formas de conviver.

No fluir de minhas reflexões, uno minha voz à de Pellanda (2016), quando ela apresenta ideias inspiradoras ao discorrer sobre o tema complexidade e invenção de si: rumo a uma integração cósmica. Ideias que corroboram 
com o que estou propondo. A autora destaca, citando Maturana e Varela (1980), que os seres humanos, por meio do uso da consciência e da autoconsciência, podem ser produtores de si mesmos. Para inferir sobre isso, esses cientistas chilenos propõem o conceito de autopoiese para mostrar que nós, humanos, podemos autoproduzir-nos entrelaçados no viver e no conhecer.

Pellanda (2016) ainda argumenta que a autoria/ autonomia dos seres humanos está diretamente ligada à sua capacidade de autoconstrução e à maestria sobre si mesmo. Essa estudiosa da complexidade enfatiza em seu ensaio inspirador que, para encontrar esse estado de maestria sobre si, que pode também, ao meu ver, ser entendido como empoderamento pessoal, como defende Freire (1987), é preciso a tomada de consciência da nossa natureza cósmica e do potencial que desta decorre. Para a pesquisadora, essa consciência é suporte para conectarmos a nossa força interna, que temos e carece ser acessada, no sentido de entrarmos em contato com esta por meio de recursos próprios, como que nos reconectando, visto que a temos em estado potencial.

\section{Palavras finais}

Ao retomar o que é o foco de minha proposta anunciada no título: "A inteireza do ser como caminho para a constituição do caminho do sujeito professor", saliento que as considerações que apresentei para iluminar a autoformação docente são pautadas em processos e em relações. Para que assim possa ser desencadeado um processo de ampliação de consciência e para que sejam criados domínios de ação nos quais os professores possam atuar em respeito mútuo e autoaceitação.

A prática de escutar a si mesmo, com abertura e amorosidade, reconhecendo as sensações que se movem no corpo, numa atitude de percepção de si, podem ser ampliadas para a sala de aula, constituindose em "laboratórios de convivência" e transformando experiências do cotidiano escolar em espaços de partilha, de escuta, de interação. Um processo no qual os professores e alunos possam aprender/reaprender a praticar o respeito por si mesmos e pelo outro. Atuando dessa forma no campo das experiências escolares, professores e alunos podem se (re)conectar com a sua capacidade de reorganização, agindo de modo criativo e empoderador e permitindo a constituição da pertença, da auto-observação e da formação de si. a partir da interação com o outro e com seu campo de atuação.

O professor percebe, ao se dar conta dessa dimensão de si, que sua forma de sentir e de atuar afeta o aluno. Quando ele atua desde outro lugar, pode criar uma nova forma de estar no campo docente, numa atitude com potencial de educar para a construção de paz e respeito, num fluir que inclui a espiritualidade. Esta, entendida como uma experiência de ampliação da consciência e de pertencimento a um âmbito mais amplo de existência.

Tomamos o entendimento de experiência espiritual, conforme Maturana e Rezepka (2000), compreendendo-a como uma ampliação da consciência, de pertencimento a um âmbito mais amplo de existência. Nesse sentido, o pertencimento (SENGE et al., 2007; WHEATLEY, 2006a) se relaciona com um estado de presença e também se funda no amor que abre o espaço de legitimidade à coexistência de tudo.

[...], pertencer tem um sentido 'duplo' [...] quando digo: 'eu pertenço', não quero dizer com isso que alguma coisa me possui, mas que eu faço parte de, e estou intimamente envolvido com uma realidade maior do que eu mesmo [...] significa: 'eu encontro meu lugar', 'é isso aí', e, ao mesmo tempo, 'aqui estou' (CAPRA et al., 1991, p. 27).

\section{REFERÊNCIAS}

ANDRADE, Isabel Cristina Feijó. A inteireza do ser: uma perspectiva transdisciplinar na autoformação de educadores. Tese (Doutorado) - Faculdade de Educação da PUCRS, Porto Alegre, 2011.

BOETTCHER, Dulce Marlise; PELLANDA, Nize Maria Campos. Vivências autopoiéticas. Santa Cruz do Sul: Edunisc, 2010.

BRUSTOLIN, Rosane Kohl; SOARES, Eliana Maria do Sacramento. Formação humana dos educadores na era digital: convivência e conversações em grupos focais. In: VII Congresso Internacional de Educação: Profissão docente: há futuro para esse ofício? 2011, São Leopoldo. Anais. Casa Leiria, 2011.

CAPRA, Fritjof et al. Pertencendo ao universo: explorações nas fronteiras da ciência e da espiritualidade. São Paulo: Cultrix, 1991.

CAPRA. Fritjof; LUISI, Pier Luigi. A visão sistêmica da vida: uma concepção unificada e suas implicações filosóficas, políticas, sociais e econômicas. São Paulo: Cultrix, 2014.

FREIRE, Paulo. Ação cultural para a libertação e outros escritos. Rio de Janeiro: Paz e Terra, 1987.

MATURANA, Humberto Romesín. Transformación en la convivencia. Santiago do Chile: Dolmen Ediciones, 2002.

MATURANA, Humberto Romesín; MAGRO, Cristina; GRACIANO, Miriam; VAZ, Nelson (Org.). A ontologia da realidade. Belo Horizonte: Ed. UFMG, 1997.

MATURANA, Humberto Romesín; MAGRO, Cristina; PAREDES, Vitor (Org. e trad.). Cognição, ciência e vida cotidiana. Belo Horizonte: Ed. UFMG, 2001.

MATURANA, Humberto Romesín; DÁVILA, Ximena Yánez. Habitar humano em seis ensaios de biologia-cultural. São Paulo: Palas Athena, 2009.

MATURANA, Humberto Romesín; REZEPKA, Sima Nisis de. Formação humana e capacitação. Petrópolis: Vozes, 2000. 
MATURANA, Humberto Romesín; VARELA, Francisco Javier. De máquinas e seres vivos - autopoiese: a organização do vivo. Porto Alegre: Artes Médicas, 1997.

MATURANA, Humberto Romesín; VARELA, Francisco Javier. Autopoiesis and cognition. Dordrecht: D. Reidel, 1980.

PELLANDA, Nize Maria Campos. Complexidade e invenção de si: rumo a uma integração cósmica. In: SOARES, E. M. S.; RECH, J. (Org.). Educação e espiritualidade: tessituras para construção de uma cultura de paz. Caxias do Sul: Educs, 2016.

SENGE, Peter et al. Presença: propósito humano e o campo do futuro. São Paulo: Cultrix, 2007.

SOARES, Eliana Maria do Sacramento; RECH, Jane. Biologia do conhecer e conversar liberador: inspirações para práticas precursoras de convivência de paz no ambiente escolar. In: SOARES, Eliana Maria do Sacramento; RECH, Jane (Org.). Educação e espiritualidade: tessituras para construção de uma cultura de paz. Caxias do Sul: Educs, 2016.
SOARES, Eliana Maria do Sacramento; VALENTINI, Carla Beatris. Docente na cultura digital: reflexões à luz da biologia do conhecer. Signo, Santa Cruz do Sul, v. 36 n. 61, p. 326-338, jul.-dez. 2011.

VARELA, Francisco Javier; THOMPSON, Evan; ROSCH, Eleanor. A mente incorporada: ciências cognitivas e experiência humana. Porto Alegre: Artmed, 2003.

WHEATLEY, Margaret. Liderança e a nova ciência: descobrindo ordem num mundo caótico. São Paulo: Cultrix, 2006a.

WHEATLEY, Margaret. Liderança para tempos de incerteza: a descoberta de um novo caminho. São Paulo: Cultrix, 2006b.

Recebido em 17-01-2018

Aprovado em 19-03-2018. 